\title{
28 Research Square \\ Classic RNA extraction is efficient for subsequent detection of SARS-CoV-2 by RT-PCR in nasopharyngeal swab samples
}

Maíra Garcia Saldanha ( $\sim$ msaldanha@unifesp.br)

Universidade Federal de São Paulo (EPM/UNIFESP)

Nayra Reis

Universidade Federal de São Paulo (EPM/UNIFESP)

Marcos Antônio Azevedo Junior

Universidade Federal de São Paulo (EPM/UNIFESP)

Manoel João Batista Castello Girão

Universidade Federal de São Paulo (EPM/UNIFESP)

Marair Gracio Ferreira Sartori

Universidade Federal de São Paulo (EPM/UNIFESP)

Luciano Kleber de Souza Luna

Universidade Federal de São Paulo (EPM/UNIFESP)

Nancy Cristina Junqueira Bellei

Universidade Federal de São Paulo (EPM/UNIFESP)

Tatiana Carvalho de Souza Bonetti

Universidade Federal de São Paulo (EPM/UNIFESP)

\section{Method Article}

Keywords: protocol, RNA extraction, SARS-CoV-2, RT-PCR

Posted Date: February 23rd, 2022

DOI: https://doi.org/10.21203/rs.3.rs-1374846/v1

License: (c) (1) This work is licensed under a Creative Commons Attribution 4.0 International License.

Read Full License 


\section{Abstract}

Background: Mass testing is a fundamental measure for tracking and controlling the spread of coronavirus disease 2019 (COVID-19) cases. The standard diagnosis for infection by severe acute respiratory syndrome coronavirus-2 (SARS-CoV-2) involves the extraction of nucleic acids for the recognition of viral genes present in biological samples collected from the population. This worldwide demand affects the distribution of specific reagents and difficult to expand the number of tests. The aim of the study was to compare the quality of the extracted material using a commercial kit and a phenolbased reagent and the reverse transcription-polymerase chain reaction (RT-PCR) results. We performed these two RNA extraction protocols with 15 samples positive for SARS-CoV-2.

Results: Our analysis showed that there was no reduction in the sensitivity of the RT-PCR test or direct impact on the diagnosis of SARS-CoV-2 infection.

Conclusions: Both methodologies proved to be useful and show similar results, confirming the possibility of using alternative RNA extraction protocols for the detection of SARS-CoV-2.

\section{Introduction}

The SARS-CoV-2 pandemic worldwide demands a sudden expansion of viral diagnostic capacity. Virus transmissibility is high by asymptomatic, pre-symptomatic or symptomatic patients with COVID-19 1 , prompting the need for large-scale tests in the entire population to track, identify and isolate clinical cases $^{2-5}$. Based on the experience of other respiratory infectious diseases, including SARS in 2003, World Health Organization (WHO) recommended a diagnostic protocol for detection of viral RNA by reaction in RT-PCR in respiratory samples ${ }^{6}$. This method consists of nucleic acid amplification, which starts from the isolation and purification of RNA from the collected sample.

Molecular biology to the extraction of biomolecules is a basic process and over time many protocols have been developed since the manual method to the offerings of commercial kits. Extraction by rotation column is based on solid phase material and solutions with low salt that facilitate the binding, washing and elution of nucleic acids. However, this material is designed for single use and the cost is higher than other purification methods ${ }^{7}$. The classic protocol of phenol-chloroform involves routine laboratory reagents. It is a monophasic solution of phenol and guanidinium isothiocyanate that solubilizes the biological material, denatures proteins, and inactivates the viruses. The commercial denomination of TriReagent (Sigma Aldrich) or TRIzol (Invitrogen) originates from three phases formed during the purification process with chloroform, which include protein in the bottom organic phase, the DNA dissolved at the interface and RNA remains in the supernatant aqueous phase ${ }^{8}$.

Despite the methodological possibilities, the high diagnostic demand during the initial COVID-19 epidemic caused a scarcity of commercial reagents for the extraction and amplification of nucleic acids, limiting testing for COVID-19. In countries in which an economic crisis has caused a health emergency 
due to the epidemic, the access to inputs is even scarcer. Moreover, the time to importation of those material is long, impairing the acquisition process. Extensive collaboration between academic, industrial and health institutions is still insufficient to support mass testing strategies ${ }^{9}$. Alternative drugs, reagents, buffers, and protocols must be explored to reduce those deficits ${ }^{10}$. The aim of this study was to standardize the RNA extraction methods to SARS-CoV-2 RT-PCR by phenol-chloroform as alternative use of column protocol for subsequent RT-PCR diagnostic test.

\section{Material And Methods}

\subsection{Study design and samples}

This study was conducted at the Laboratory of Molecular Gynaecology of the Gynaecology Department Federal University of Sao Paulo - Paulista School of Medicine (UNIFESP-EPM), São Paulo - Brazil, from May to December 2020. Fifteen nasopharyngeal swab collection samples from SARS-CoV-2 positive individuals reserved in ringer lactato were used in this study. All samples were positive for SARS-CoV-2 diagnosed by quantitative PCR at the Virology Laboratory of the Medicine Department at UNIFESP-EPM, São Paulo - Brazil. For the standard diagnosis, viral RNA was purified by gold standard column method Extracta kit - DNA e RNA Viral (Loccus, São Paulo, Brazil) and the quantitative PCR used the GeneFider COVID-19 Plus RealAmp kit (Osang Healthcare, Gyeonggi, South Korea).

All samples were reanalysed in the Laboratory of Molecular Gynaecology of UNIFESP-EPM. Samples were split into two aliquots and had RNA purification performed by the gold standard column method and phenol-chloroform method in parallel. Both RNA extracted for each sample were submitted to quantitative RT-PCR by in-house standardized method following CDC guidance ${ }^{20}$.

\subsection{RNA extraction using commercial column extraction kit}

The RNA purification was performed using the PureLink Viral RNA/DNA Mini Kit (Invitrogen, California, USA). A volume of 200ul of nasopharyngeal swab samples reserved in ringer lactato was used as starting material. The protocol followed the manufacturer instructions, and the RNA was eluted in $60 \mu$ of RNase free water and cryopreserved at $-80^{\circ} \mathrm{C}$.

\subsection{RNA extraction using phenol-chloroform method}

For the extraction of viral RNA by the phenol-chloroform method, we used the TriReagent ${ }^{\circledR}$ (Invitrogen, California, USA) and the protocol followed the manufacturer instructions. The starting material was 200ul of nasopharyngeal swab samples reserved in ringer lactate and followed the manual instructions. Briefly, it was added $1 \mathrm{~mL}$ of TriReagent ${ }^{\circledR}$ (Invitrogen, California, USA) in $200 \mu$ of the sample, followed by the addition of $200 \mu \mathrm{L}$ of chloroform, $2 \mu \mathrm{L}$ of glycogen, $500 \mu \mathrm{L}$ of isopropanol. During the process, the reagents were kept on ice. After homogenization, the solution was incubated for 10 minutes and centrifuged at $12,000 \mathrm{xg}$ for than 10 minutes at $4^{\circ} \mathrm{C}$. The supernatant was removed, and the pellet was resuspended in $1 \mathrm{~mL}$ of absolute ethyl alcohol. Another centrifugation was carried out at $7500 \times \mathrm{g}$ for 5 
minutes at $4^{\circ} \mathrm{C}$ and the supernatant was removed. The RNA pellet was dried at room temperature as an open tube on absorbent paper for 5 to 10 minutes. The RNA was eluted in $40 \mu$ of RNase free water and incubated for 15 minutes in a dry bath at $60^{\circ} \mathrm{C}$.

\subsection{Measurement of purity and concentration of extracted RNA}

Immediately after each RNA purification for both column and phenol-chloroform methods, the concentration and purity of RNA was measured using the Nanodrop microvolume spectrophotometer (ThermoFisher Scientific, Massachusetts, USA) using $1 \mu \mathrm{L}$ of each sample at a time and readings were done at 260 and $280 \mathrm{~nm}$ wavelength. At an absorbance rate of 260/280, the calculation of the optical density ratio was used to determine the purity of RNA and the presence of contaminants in biological evidence during the extraction process.

\subsection{Real time PCR (RT-PCR)}

The two RNA samples purified by column and phenol-chloroform methods were run in the same experiment of quantitative RT-PCR in parallel. The AgPath-ID One-Step RT-PCR Kit (Applied Biosystems, California, USA) was used for the amplification reaction following the manufacturer instructions. In each analysis, the total reaction volume of $25 \mu \mathrm{L}$ contained the Primer Forward, Primer Reverse, Enzyme Mix and $5 \mu \mathrm{L}$ of sample. The amplification process used the Step One Plus Real Time System (Applied Biosystems California, USA) with the following temperature variation: $50^{\circ} \mathrm{C}$ for 10 minutes, $95^{\circ} \mathrm{C}$ for 10 minutes for reverse transcription, followed 45 times is $95^{\circ} \mathrm{C}$ for 15 seconds and $55^{\circ} \mathrm{C}$ for 30 seconds.

The RT-PCR was standardized according to the parameters specified by the CDC/USA protocol. The targets were: 2019-nCOV_N1-F (GACCCCAAAATCAGCGAAT). 2019-nCOV_N1-R (TCTGGTACTGCAGTTGAATCTG), 2019-nCOV_N2-F (TTACAAACATTGGCCGCAAA), 2019-nCOV_N2-R (GCGAGNAGA foci identifies RPGA and viral TCCNAGNA-R (GCGAGNAGA foci RPGA_N2-R) (GCGAGNAGA foci identifies viral RPGA-R) F (AGATTTGGACCTGCGAGCG) and RP-R (GAGCGGCTGTCTCCACAAGT).

The result of quantitative PCR was presented as cycle limit (Ct) which indicates the cycle number where the amplification line crosses or the specified limit. Ct's less than 40 were considered positive.

\subsection{Data analysis}

For the comparisons of the efficacy of two methods for RNA purification, two conditions were analysed. Firstly, the evaluated the RNA yield observed in the quantification after purification by using column and phenol-chloroform methods. In a second step of the analysis, the outcomes of quantitative PCR were compared based on Ct values. Numerical variables were presented as means and standard deviation (SD). The statistical tests used paired and non-parametrical tests due to small number of samples. The GraphPad Prism 5 software and R through the RStudio interface (version 1.2.5019) were used to statistical analysis. 


\section{Results}

Two different protocols were established for RNA extraction, using a previously standardized method as extraction kit by column from PureLink Viral RNA/DNA Mini Kit (Invitrogen, California, USA) and by phenol-chloroform using TriReagent ${ }^{\circledR}$ (Invitrogen, California, USA), both following the manufacturer's protocol.

A comparative scheme between the two extraction protocols follows in Table 1. The initial volume was $200 \mathrm{ul}$ of sample for both protocols, the digestion stage was performed with chloroform, glycogen, isopropanol with TriReagent, while a buffer solution and proteinase $\mathrm{K}$ was available in the column kit. The incubation stage varied from 15 to 10 minutes at a temperature of $56^{\circ} \mathrm{C}$ and $4^{\circ} \mathrm{C}$, respectively. During the extraction by column, the reagents were at room temperature, the entire extraction process as TriReagent was performed at a temperature of $4^{\circ} \mathrm{C}$ with the reagents kept on ice and using a refrigerated centrifuge. After incubation, an additional stage of centrifugation at $12000 \mathrm{x} \mathrm{g}$ for 10 minutes was necessary for extraction with TriReagent. The volumes of ethanol, time and speed of centrifugation and volume of elution in free RNase water were different between the two protocols with phenol and by column, respectively. After the elution, the protocol by column is concluded, meanwhile extraction as TriReagent requires an additional incubation stage for 15 minutes in a dry bath at $60^{\circ} \mathrm{C}$. This last method has more stages and incubation periods, therefore it was performed for 45 minutes, when compared to extraction per column that takes approximately 20 minutes per sample. 
Table 1

Comparison between the RNA extraction protocols by column kit and phenol-chloroform methods.

\begin{tabular}{|lll|}
\hline Methods & Column Kit & Phenol-chloroform \\
\hline Reagent & $\begin{array}{l}\text { PureLink Viral RNA/DNA } \\
\text { Mini Kit }\end{array}$ & TriReagent ${ }^{\circledR}$ \\
\hline Sample volume for extraction & $200 \mathrm{uL}$ & $200 \mathrm{uL}$ \\
\hline & $25 \mathrm{uL}$ Proteinase $\mathrm{K}$ & $200 \mu \mathrm{L}$ of chloroform, \\
& $200 \mathrm{uL}$ lise buffer & $2 \mu \mathrm{L}$ of glycogen \\
\hline Incubation & & $500 \mu \mathrm{L}$ of isopropanol \\
\hline Centrifugation & $15 \mathrm{~min}$ at $56^{\circ} \mathrm{C}$ & $1 \mathrm{~mL}$ of TriReagent \\
\hline Ethanol & none & $10 \mathrm{~min}$ at $4^{\circ} \mathrm{C}$ \\
\hline Centrifugation & $250 \mu \mathrm{L}$ & $12,000 \times \mathrm{g}$ for $10 \mathrm{~min}$ at \\
\hline Elution in RNase free water & $6800 \mathrm{~g}$ for $1 \mathrm{~min}$ & $1 \mathrm{~mL}$ \\
\hline Incubation & $40 \mu \mathrm{l}$ & $7,500 \times \mathrm{g}$ for 5 min \\
\hline $\begin{array}{l}\text { Approximated preparation time (for } 15 \\
\text { samples) }\end{array}$ & $20 \mathrm{~min}$ & $60 \mu \mathrm{l}$ \\
\hline
\end{tabular}

\subsection{Quantification and purity of RNA}

When comparing the results of the RNA extraction of the 15 samples used for the analyses, a high discrepancy was found in the nucleic acid values between the methods. In the extraction by column, the mean concentration of RNA purified was $13.6 \pm 3.2 \mathrm{ng} / \mu \mathrm{L}$, while the extraction with phenol-chloroform was $349.0 \pm 41.4 \mathrm{ng} / \mu \mathrm{l}(\mathrm{p}<0.0001)$ (Figure $1 \mathrm{~A})$. Regards the absorbance rate of $260 / 280 \mathrm{~nm}$ demonstrated similar levels of purity of the extracted material ( $(1.8 \pm 0.1$ for extraction per column and $1.8 \pm 0.0$ with phenol-chloroform, $\mathrm{p}=0.5$ ) (Figure 1B).

\subsection{Real time-PCR for SARS-CoV-2}

The commercial AgPath-ID One-Step RT-PCR Kit (Applied Biosystems, California, USA) was used for the detection of SARS-CoV-2 by RT-PCR, together with probes that allow simultaneous amplification of two genes from viruses (N1 and N2) and an internal endogenous gene control (RP). According to the US CDC panel, Ct's under 40 are considered positive and absent are negative. Thus, all observed samples were 
within two parameters of positivity for at least one gene. The N1 genes show a mean \pm SD of Ct's of 26.6 \pm 2.0 in extraction by column and $24.5 \pm 3.5,(p=0.1)$ in extraction with phenol-chloroform. Further, N2 gene with Ct's of $20.8 \pm 2.5$ and $22.1 \pm 2.7$, ( $p=0.7)$ by column and phenol-chloroform, respectively. Endogenous control was also positive and there was no difference between the $\mathrm{Ct}$ on two RNA extraction methods, $30.1 \pm 0.8$ and $35.2 \pm 0.5,(p=0.2)$ (Figure 2).

To identify the correlation between extracted RNA and Ct number, we performed Spearman's test and confirmed that the difference in the initial RNA concentration, observed between column and phenolchloroform methods, did not interfere with Ct's amplification (Figure 3). Moreover, no correlation was observed between the Ct's of genes N1 and N2 regardless of the RNA concentration of each sample extracted by the column (Figure $3 \mathrm{~A}$ and $3 \mathrm{~B}$ ) and phenol-chloroform (Figure $3 \mathrm{C}$ and $3 \mathrm{D}$ ) extraction methods.

\section{Discussion}

The new coronavirus pandemic (SARS-CoV-2) quickly demanded the performance of diagnostic tests to track the spread of the virus in the world population. This has an impact on the implementation of different protocols for the expansion of the capacity of public and private institutions to perform exams that require specialized work management and infrastructure, as well as the use of high-cost inputs, many times imported ${ }^{11}$. Currently the diagnosis by RT-PCR is considered as the WHO reference standard for infection by SARS-CoV-2 and nucleic acid extraction is the first stage for the RT-PCR performance, ${ }^{12}$. This study compared the phenol-chloroform protocol, which is older, classic and manual method for RNA purification with the extraction by column is possible with silica membrane technology that allows rapid purification of nucleic acids, which is considered gold standard method for SARS-CoV-2 RNA purification and RT-PCR.

Phenol-chloroform protocol causes rupture of cell membranes containing the release of genetic material from the virus. Either alcohol solubilizes RNA, when repeated centrifugations isolate the nucleic acids of the cellular debris and, finally, the precipitated RNA and solubilized in RNase free water ${ }^{13}$. In contrast, the commercial kit of extraction by column is possible with silica membrane technology that allows rapid purification of nucleic acids, without interference of contaminants and manipulation of potentially dangerous buffers ${ }^{14}$. This study, the column kit was used in accordance with the manufacturer's instructions, incorporates previous reports to allow for the possibility of protocol adjustments to optimize the yield of reagents obtaining lower values of $\mathrm{Ct}$ in viral gene amplification ${ }^{15}$. Despite the higher time for the development of the protocol, the handling of toxic reagents and the need for the use of a refrigerated centrifuge, the extraction method by phenol-chloroform proved convenient, once during a pandemic there was an increased consumption of extraction kits that caused the scarcity of these inputs and a disproportionate rise in prices.

We verified the concentration and purity of the RNA extracted from two methods using the NanoDrop spectrophotometer, a useful and worldwide diffused mode to estimate these parameters. This system 
works with the retention of a sample microvolume by combining optical fibber technology and surface tension, avoiding the need for additional steps, dilution and use of capillary cuvettes ${ }^{16}$. Consequently, it reduces the interference of handling and decalibration in molecular levels, reducing or controlling the quality and efficiency of the analysis. Despite of have been discussed that column extraction method is more efficient due it is cleaner, we have observed a RNA concentration twenty times greater in phenolchloroform with a similar level of purity. The high concentration observed in phenol-chloroform method can be justified as it extracts the total RNA from the samples, while the kit per column is specific for viral RNA extraction.

The last step of the process consisted of detecting the SARS-CoV-2 RNA by RT-PCR. The primers used have allowed the hybridization and amplification of the sequence for the fluorescent probes, emitting a signal that was captured by the equipment, confirming the positivity of the presence of the SARS-CoV-2 in the sample. The genes amplified in the developmental cycle originate from the SARS-CoV-2 gene, called $\mathrm{N} 1$ and N2, specific regions that are highly expressed and maintained during the viral replication phase of the coronavirus ${ }^{17,18}$, in addition to the RP gene, an endogenous control marker of metabolism in human cells. Despite of the RNA concentration obtained by the column was much lower than phenol-chloroform, it did not interfer with the correlation with $\mathrm{Ct}$ levels. This can be explained by the PCR kit having a limit of amplification capacity, which is reached with samples extracted by the column, of lower concentration, and therefore, a higher RNA input will not cause any alteration in the process.

A limitation of this study was the samples used had an average of Ct's near to 20 and we did not have available samples with higher Ct's. Possibly, samples with a low viral load would be more sensitive to the phenol-chloroform method. Also, we did not include negative samples to attest to the correct application of this diagnostic test in the absence of a virus. However, a false-negative result was not found with the positive samples included a vantage of recognition of two target genes, albeit the importance of the period of the queue of the patient shown. A queue of secretions from the upper airways by means of nasopharyngeal and oropharyngeal swabs are considered suboptimal ${ }^{19}$ and capable of early diagnosis of the symptoms of COVID-19 20 .

We know that there are other recent molecular approach techniques such as the use of automated systems or the elimination of the extraction stage, which require specific commercial kits and significantly increase the cost of fines ${ }^{21,22}$. Nevertheless, the focus of this study was to expand the diagnostic confirmation alternatives while maintaining the security and quality of the tests. Considering the importance of precise and interpretive results, regardless of whether the tests will be performed with conventional or advanced molecular diagnostic protocols, we confirm that the extraction method with phenol-chloroform presents biosecurity and additional economic advantage over commercial kits. This method can instantly activate viral particles, allowing the protocol to be executed by a laboratory with a level II biosecurity cabinet ${ }^{23}$, which can be tested on a variety of biological samples collected for diagnosis, including saliva, bronchoalveolar lavage, excreta, and tissues. 
In conclusion, there are no statistically significant differences in the results of the RT-PCR of both the validated methods, showing that substituting the extraction for column can be performed using the phenol-chloroform protocol without reducing the sensitivity of the test nor impact directly on the diagnosis of the SARS-CoV-2 infection.

\section{Declarations}

\section{Funding}

This research did not receive any specific grant from funding agencies in the public, commercial, or notfor-profit sectors.

\section{Ethical Approval and Consent to participate}

The study and informed consenting term were submitted and approved by Institutional Review Board (Ethics Committee of Federal University of São Paulo CEP-UNIFESP) and National Committee of Ethics in Research (Comitê Nacional de Ética em Pesquisa - CONEP), Process Number: 4.059.761, CAEE: 30683320.7.0000.5505.

\section{Consent for publication}

Consent forms were taken and signed.

\section{Availability of data and materials}

Not applicable.

\section{Competing interests}

The authors report no conflict of interest.

\section{Authors' contributions}

MGS, NR and TCSB designed the study and wrote the manuscript with significant input from MGFS, MJBCG, LKSL and NCJB. MGS, MAAJ and TCSB did the statistical analyses. All authors contributed to interpretation of data and revised and approved the manuscript.

\section{Acknowledgements}

We thank the Laboratory of Virology of Federal University of São Paulo for collecting the exams.

\section{Authors' information}

Maíra Garcia Saldanha, PhD; Nayra Reis, BSc; Marcos Antônio Azevedo Junior, PhD; Manoel João Batista Castello Girão, MD, PhD; Marair Gracio Ferreira Sartori, MD, PhD; Luciano Kleber de Souza Luna, PhD; 
Nancy Cristina Junqueira Bellei, MD, PhD; Tatiana Carvalho de Souza Bonetti, PhD.

\section{References}

1. Zou, L. et al. SARS-CoV-2 Viral Load in Upper Respiratory Specimens of Infected Patients. N. Engl. J. Med. (2020) doi:10.1056/nejmc2001737.

2. Giordano, G. et al. Modelling the COVID-19 epidemic and implementation of population-wide interventions in Italy. Nat. Med. (2020) doi:10.1038/s41591-020-0883-7.

3. Peto, J. Covid-19 mass testing facilities could end the epidemic rapidly. The BMJ (2020) doi:10.1136/bmj.m1163.

4. Balilla, J. Assessment of COVID-19 Mass Testing: The Case of South Korea. SSRN Electron. J. (2020) doi:10.2139/ssrn.3556346.

5. Oran, D. P. \& Topol, E. J. Prevalence of Asymptomatic SARS-CoV-2 Infection: A Narrative Review. Annals of internal medicine (2020) doi:10.7326/M20-3012.

6. Corman, V. M. et al. Detection of 2019 novel coronavirus (2019-nCoV) by real-time RT-PCR. Eurosurveillance (2020) doi:10.2807/1560-7917.ES.2020.25.3.2000045.

7. Shi, R., Lewis, R. S. \& Panthee, D. R. Filter paper-based spin column method for cost-efficient DNA or RNA purification. PLoS One (2018) doi:10.1371/journal.pone.0203011.

8. Rio, D. C., Ares, M., Hannon, G. J. \& Nilsen, T. W. Purification of RNA using TRIzol (TRI Reagent). Cold Spring Harb. Protoc. (2010) doi:10.1101/pdb.prot5439.

9. Jayamohan, H. et al. SARS-CoV-2 pandemic: a review of molecular diagnostic tools including sample collection and commercial response with associated advantages and limitations. Analytical and Bioanalytical Chemistry (2021) doi:10.1007/s00216-020-02958-1.

10. Esbin, M. N. et al. Overcoming the bottleneck to widespread testing: A rapid review of nucleic acid testing approaches for COVID-19 detection. RNA (2020) doi:10.1261/rna.076232.120.

11. Chhikara, K. et al. Validation of SARS CoV-2 detection by real-time PCR in matched pooled and deconvoluted clinical samples before and after nucleic acid extraction: a study in tertiary care hospital of North India. Diagn. Microbiol. Infect. Dis. (2021)

doi:10.1016/j.diagmicrobio.2020.115206.

12. WHO. Advice on the use of point-of-care immunodiagnostic tests for COVID-19 Rapid diagnostic tests based on antigen detection. WHO Coronavirus disease (COVID-19) Pandemic (2020).

13. Chomczynski, P. \& Sacchi, N. The single-step method of RNA isolation by acid guanidinium thiocyanate-phenol-chloroform extraction: Twenty-something years on. Nat. Protoc. (2006) doi:10.1038/nprot.2006.83.

14. Azzi, L. et al. Diagnostic Salivary Tests for SARS-CoV-2. Journal of Dental Research (2021) doi:10.1177/0022034520969670.

15. Ambrosi, C. et al. SARS-CoV-2: Comparative analysis of different RNA extraction methods. J. Virol. Methods (2021) doi:10.1016/j.jviromet.2020.114008. 
16. Desjardins, P. \& Conklin, D. NanoDrop microvolume quantitation of nucleic acids. J. Vis. Exp. (2010) doi: $10.3791 / 2565$.

17. Moreno, J. L., Zúñiga, S., Enjuanes, L. \& Sola, I. Identification of a Coronavirus Transcription Enhancer. J. Virol. (2008) doi:10.1128/jvi.02622-07.

18. Zhang, T., Wu, Q. \& Zhang, Z. Probable Pangolin Origin of SARS-CoV-2 Associated with the COVID-19 Outbreak. Curr. Biol. (2020) doi:10.1016/j.cub.2020.03.022.

19. Lippi, G., Simundic, A. M. \& Plebani, M. Potential preanalytical and analytical vulnerabilities in the laboratory diagnosis of coronavirus disease 2019 (COVID-19). Clinical Chemistry and Laboratory Medicine (2020) doi:10.1515/cclm-2020-0285.

20. Centers for Disease Control and Prevention. Interim guidelines for collecting, handling, and testing clinical specimens from persons for coronavirus disease 2019 (COVID-19). Centers Dis. Control Prev. (2020).

21. Lázaro-Perona, F. et al. Evaluation of two automated low-cost RNA extraction protocols for SARSCoV-2 detection. PLoS One (2021) doi:10.1371/journal.pone.0246302.

22. Merindol, N. et al. SARS-CoV-2 detection by direct rRT-PCR without RNA extraction. J. Clin. Virol. (2020) doi:10.1016/j.jcv.2020.104423.

23. Won, J. et al. Development of a laboratory-safe and low-cost detection protocol for SARS-CoV-2 of the Coronavirus Disease 2019 (COVID-19). Exp. Neurobiol. (2020) doi:10.5607/en20009.

\section{Figures}


(A)

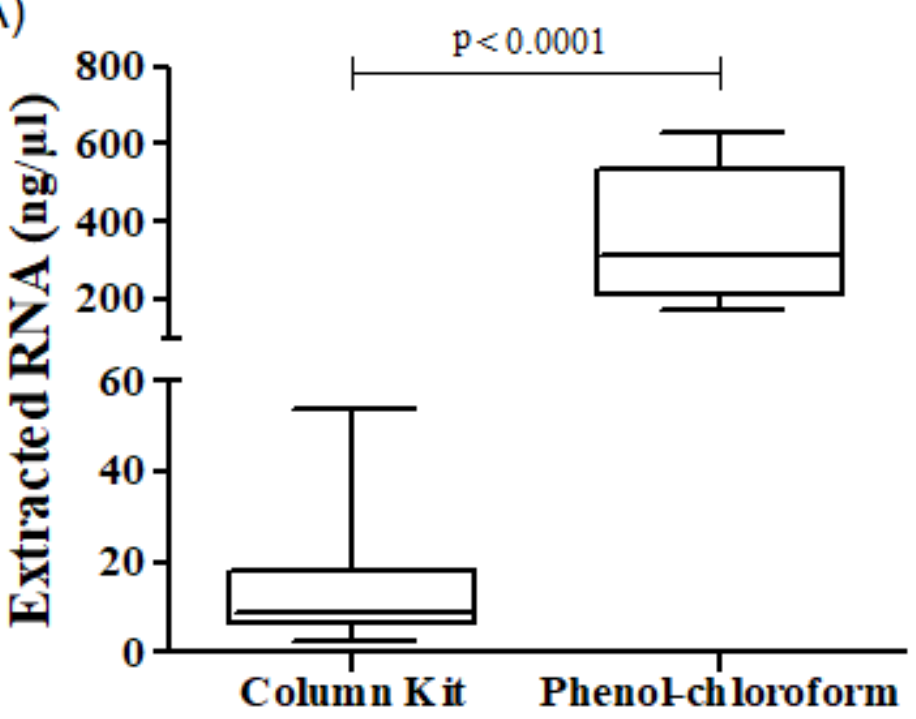

(B)



Figure 1

Concentration and purity of nucleic acids resulting from two RNA extraction tests determined by Nanodrop. (A) Comparison of two values of extracted RNA and (B) the levels of purity in $\mu \mathrm{g} / \mu \mathrm{l}$ of sample using the PureLink Viral RNA/DNA Mini Kit column protocol using or phenol-chloroform. It was used Wilcoxon matched paired test for a statistical comparison. 




Figure 2

Comparison of the threshold cycle in the detection of SARS-CoV-2 genes from RNA extracted from nasopharyngeal swabs using two methods. Was performed an extraction protocol by PureLink Viral RNA/DNA Mini Kit column and using the phenol-chloroform. The samples were analyzed by RT-PCR through AgPath-ID One-Step RT-PCR Kit. Ct's $>40$ were considered positive. We used a Wilcoxon matched paired test for a statistical comparison. $P$ values not significant. The bars represent mean/SD. $N=15$. 
(A)

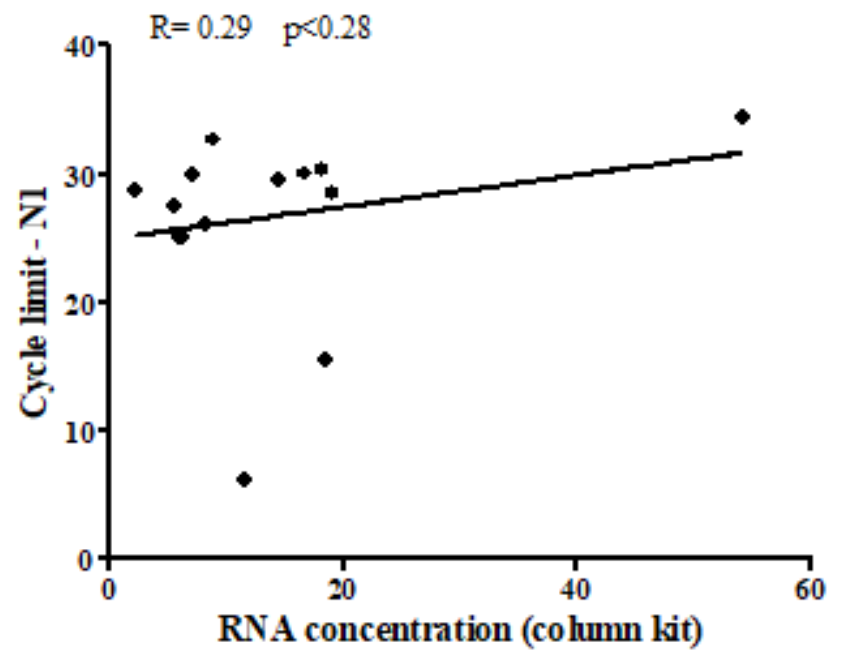

(C)

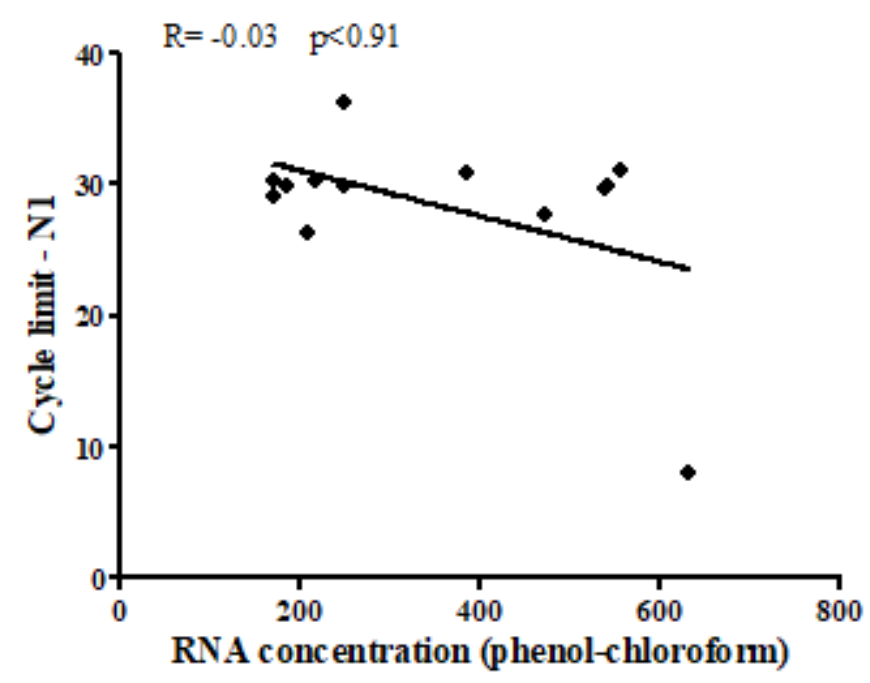

(B)



(D)

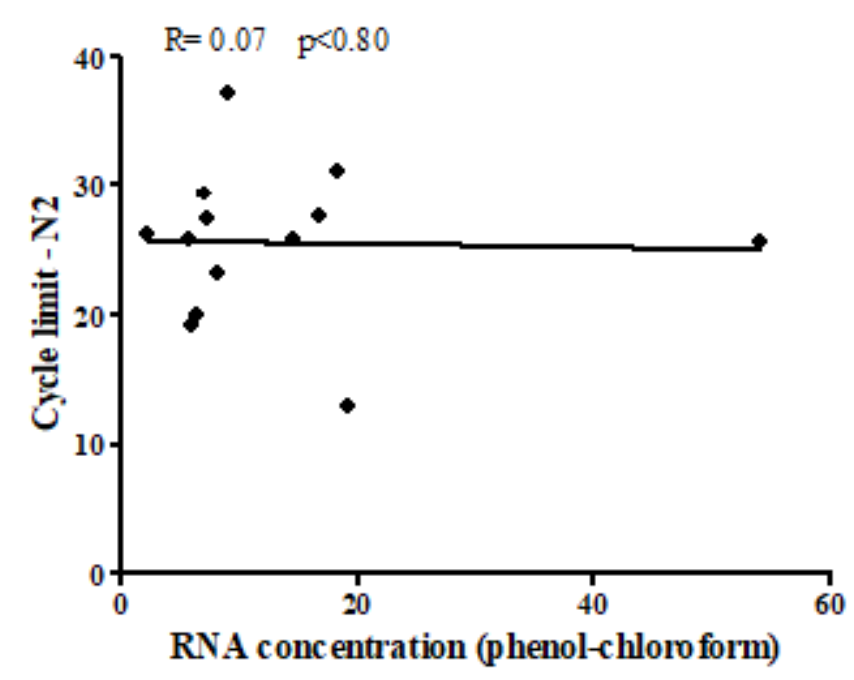

\section{Figure 3}

Spearman linear correlation between the RNA concentration extracted by ( $A$ and B) column kit and ( $C$ and D) phenol chloroform and respective $\mathrm{Ct}$ limits of target genes $\mathrm{N} 1$ and $\mathrm{N} 2$. ( $\mathrm{N}=15)$ 